\title{
Large Calcified Mass on the Mitral Annulus
}

\author{
Nobuhisa Watanabe, RDCS*, Manabu Taniguchi, MD**, Takeshi Maruo, MD**, \\ Masato Murakami, MD**, Norihisa Tou, MD**, Yasuharu Tanabe, RDCS*, \\ Katsumasa Miyaji, MD**, Kengo Kusano, MD**, Norio Koide, MD*** and \\ Tohru Ohe, MD** \\ * Department of Central Clinical Laboratory, Okayama University Hospital of Medicine and \\ Dentistry, Okayama, Japan \\ ** Department of Cardiovascular Medicine, ${ }^{* * *}$ Department of Laboratory Medicine, Okayama \\ University Graduate School of Medicine and Dentistry, Okayama, Japan
}

\begin{abstract}
Summary
We report a case with a large calcified mass on the posterior annulus of the mitral valve. Transthoracic echocardiography (TTE) showed a large, round, and echo-dense mass with central echolucencies resembling liquefaction. TTE was useful in establishing the diagnosis of caseous calcification of the mitral annulus.
\end{abstract}

(J Echocardiogr 2005; 3: 123-124)

Key words: transthoracic echocardiography, caseous calcification, mitral annulus

A 76-year-old woman with hypertension, hypercholesteremia, and diabetes mellitus was referred to our institution for suspected intraventricular mass before noncardiac surgery. She had no history of renal diseases. Her physical examination revealed a pulse of 76 beats/min, a blood pressure of $134 / 70 \mathrm{mmHg}$, and a body temperature of 36.7 degrees $\mathrm{C}$. Her cardiovascular and neurological examinations were normal. A blood test on inflammatory markers was within normal ranges. No evidence of neoplasm could be identified on computed tomography.

Transthoracic echocardiography (TTE) demonstrated a large calcified mass $(24 \times 22 \mathrm{~mm})$ on the posterior annulus. The calcified mass on the annulus was defined as a round, echo-dense mass with smooth bor-

Received August 22, 2005; revision received October 2, 2005; accepted October 14, 2005

Address for correspondence: Manabu Taniguchi, MD

Department of Cardiovascular Medicine, Okayama University Graduate School of Medicine and Dentistry,

2-5-1, Shikata-cho, Okayama 700-8558, Japan.

Telephone: +81-86-235-7351

Fax: +81-86-235-7353

E-mail: tmnb@md.okayama-u.ac.jp

(C) 2005 Japanese Society of Echocardiography ders, without strong acoustic shadowing artifacts. In addition, it contained central areas of echolucencies resembling liquefaction (Figure 1). No flow was detected in the central zone by color Doppler. There was no associated mitral valvular dysfunction caused by the mass. The left ventricular function was normal (ejection fraction: 60\%).

Further assessment was performed using transesophageal echocardiography (TEE). The mass was located in the posterior region at the junction between the left atrium and the left ventricle (Figure 2).

In our case, the mass had the typical echocardiographic features of caseous calcification of the mitral annulus reported previously [1,2]. Because this patient had no severe mitral stenosis and mitral regurgitation, she was treated conservatively.

Caseous calcification of the mitral annulus is a rare condition [1-3]. It is difficult to suspect the presence of caseous calcification of the mitral annulus according to clinical manifestations because the backgrounds of patients with caseous calcification are similar to those with mitral annular calcification [1]. Because caseous calcification is not recognized widely, it may be mistaken as other conditions requiring heart surgery, such as 


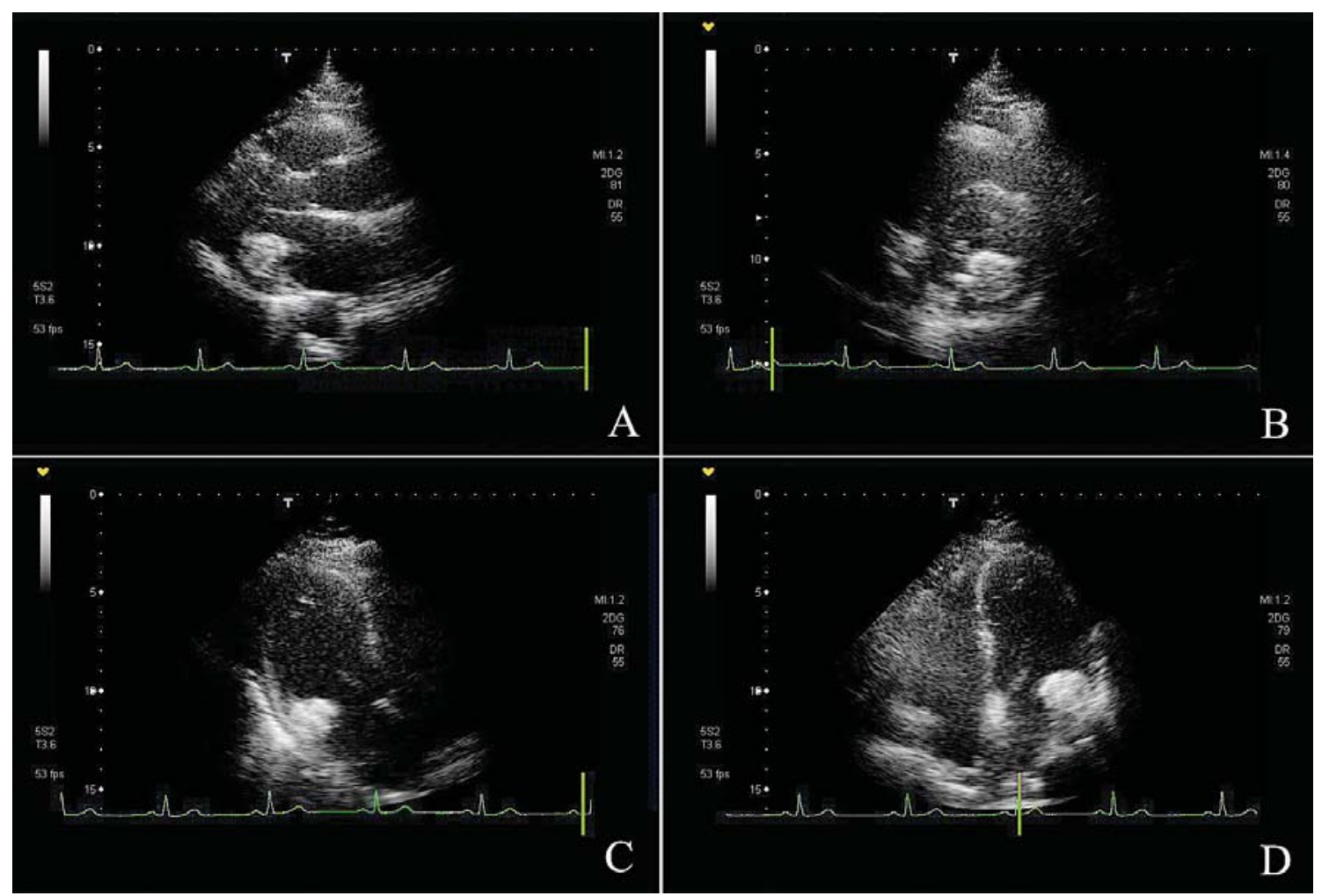

Fig. 1. Transthoracic echocardiograms

The calcified mass on the posterior annulus was defined as a large, round, and echo-dense mass with central echolucencies resembling liquefaction. (A; Parasternal long axis view, B; Parasternal short axis view, C; Apical long axis view, D; Apical 4 chamber view)

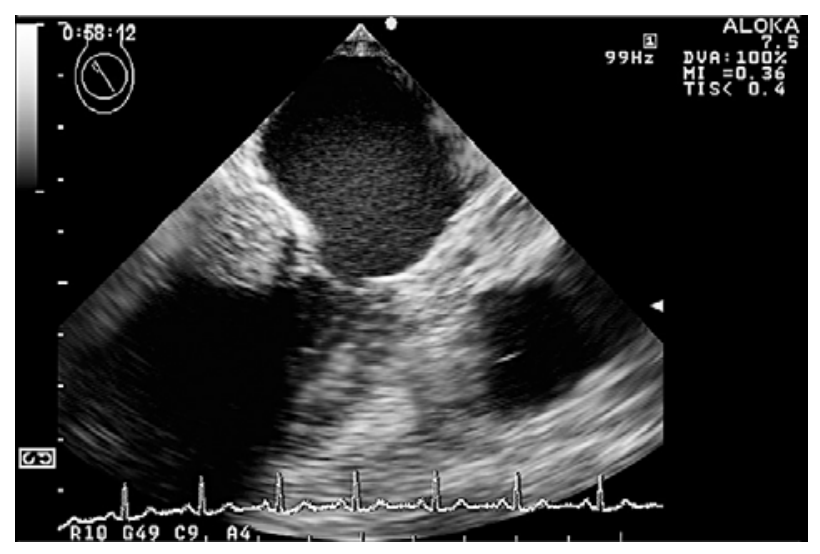

Fig. 2. Transesophageal echocardiogram

The calcified mass was located in the posterior region at the junction between the left atrium and the left ventricle, without strong acoustic shadowing artifacts. cardiac abscesses or tumors. TTE was very useful in establishing the diagnosis of caseous calcification of the mitral annulus.

\section{References}

1. Harpaz D, Auerbach I, Vered Z, et al. Caseous calcification of the mitral annulus: a neglected, unrecognized diagnosis. J Am Soc Echocardiogr 2001; 14: 825-831.

2. Novaro GM, Griffin BP, Hammer DF. Caseous calcification of the mitral annulus: an underappreciated variant. Heart 2004; 90: 388.

3. Morgan-Hughes G, Zacharkiw L, Roobottom C, et al. Tumor-like calcification of the mitral annulus: diagnosis with multislice computed tomography. Circulation 2003; 107: 355-356. 